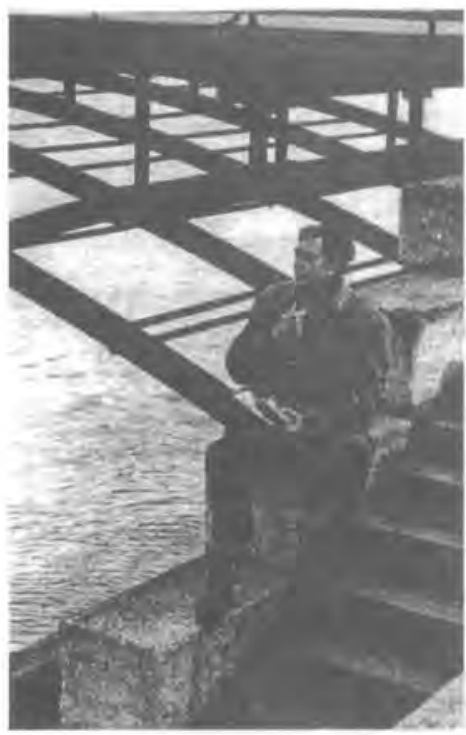

\section{Cortázar, el perseguidor}

Alicia Saliva

(Universidad Complutense de Madrid)

A vida é a arte do encontro Embora haja tanto desencontro pela vida... (Vinícius de Moraes, Samba da bênção)

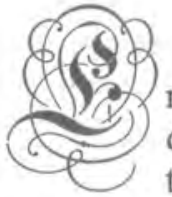

n El perseguidor, la 'rayuelita' marca un nuevo rumbo en la obra de Julio Cortázar: el autor desplaza los elementos a los que nos tenía acostumbrados en Bestiario o en Final del juego, para dejar paso a una única figura, que no es la de sagaces mancuspias, ni la de las patitas de una cucaracha escapándose por los lados de un bombón, ni la de conejitos blancos, negros y grises saliendo de la boca de un hombre. En medio de El perseguidor y como único interés de sus treinta páginas, existe el hombre Charlie Parker.

Cortázar elige este personaje para su cuento después de leer una biografia del famoso jazzman y enterarse de sus periodos de locura, de su hija muerta, de sus problemas de familial. El músico negro que había revolucionado la historia del jazz resumía la complejidad del hombre que Cortázar estaba buscando para su personaje; complejo y extravagante, Charlie Parker es una excepción más a las reglas, como tantos de los seres que ocupan la ficción cortazariana. Loco, suicida, drogadicto y visionario, pero querible, admirable, con una vida mucho más deseable que la de los cuerdos que le rodean. Así son, por lo general, los personajes centrales de Cortázar, criaturas extremas que, en palabras de Mario Vargas Llosa, "entre los resquicios de sus extravagancias, siempre dejan entrever algo que los redime y justifica: una insatisfacción con lo existente, una confusa búsqueda

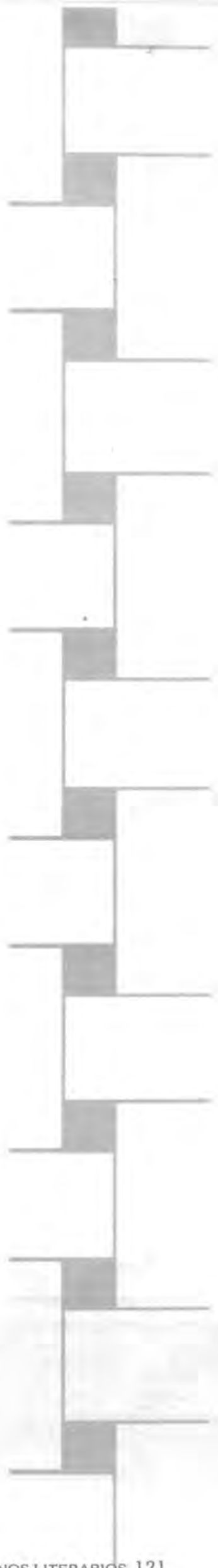


de otra vida, más imprevisible y poética (a veces pesadillesca) que aquella en la que estamos confinados".2.

Este hombre es el centro, un hombre que encarna la fórmula que Cortázar empleará en tantas ocasiones para la construcción de sus personajes: un instinto desbocado, una fuerza irracional sin tregua que tiene como justificación, como causa, como aguijón que lo hace galopar al hombre hacia esos callejones sin salida, una terrible y temible pregunta por la vida, una insatisfacción con el orden reinante como la que manifiesta Charlie Parker. Y por eso, como afirma Vargas Llosa, los lectores nos ponemos de su lado, del lado de este tipo de hombres a los que se les perdona cualquier bestialidad porque hacen lo que hacen impulsados por una insatisfacción, que sentimos también nuestra. Porque a ellos las costumbres, como a todos, nos ahogan. Y aunque no nos animemos, como no se anima Bruno, el amigo racional de Charlie, a tirarse de cabeza contra la pared, cualquier hecho brutal estaría justificado por la abrumadora presencia de esa pregunta, de esa insatisfacción.

El hombre, entonces, es el eje de este relato. El género humano, que Cortázar dice haber mirado muy poco hasta que, en 1959, escribe El perseguidor, probando desplazarse de lo fantástico e internarse en este espacio donde no se siente seguro, el hombre:

Cuando escribí El perseguidor había llegado un momento en que sentí que debía ocuparme de algo que estaba mucho más cerca de mí mismo. En ese cuento dejé de sentirme seguro [...] quise renunciar a toda invención y ponerme dentro de mi propio terreno personal, es decir, mirarme un poco a mí mismo. Y mirarme a mí mismo era mirar al hombre, mirar también a mi prójimo ${ }^{3}$.

Sin embargo, como lectores de Bestiario o de Final del juego, no sentimos ausente en estos textos la preocupación por la condición del hombre, como no lo siente Jorge Luis Borges al decir que en los primeros cuentos de Cortázar "el autor nos atrae a su terrible mundo, en que la dicha es imposible ${ }^{\natural 4}$. ¿Por qué, entonces, afirma Julio Cortázar que es en este punto de inflexión de su narrativa cuando ha empezado a internarse en ese terreno inseguro que es el hombre? ¿De qué hombre comienza a hablarnos en El perseguidor, indagación que profundiza en Los premios y en Rayuela?

Como viene aleccionándonos Umberto Eco desde hace ya bastantes

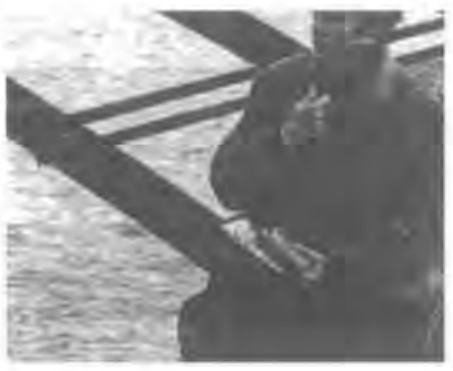
años, el escritor se autocita y reescribe en sus textos, y prescindir de esta red significa una disminución de nuestras posibilidades lectoras, La obra crítica de Cortázar, como uno de los importantes vectores de su intertextualidad, y su obra epistolar, como género que suscita el pensamiento íntimo, nos aportan materiales que iluminan este cambio en la obra de Julio Cortázar en la representación de lo humano, diferencia gracias a la cual hoy tenemos entre manos Elperseguidor, y, porqué no, Rayuela. 
En Teoria del túnel, escrita entre el verano y la primavera del año 47 (diez años de camino to separan de El perseguidor) como autor comprometido con el surrealismo y el existencialismo, Cortázar tiene ideas sobre el arte y el hombre que subyacen en sus primeros cuentos, publicados en el año '51. En este compendio de teoría, mezcla de poética personal, teoría de la literatura y manifiesto surrealista, nacidos en la preparación de las clases que había dictado dos años antes en la Universidad de Cuyo, va desgranando los postulados del movimiento que había empezado a formar parte de su actitud vital, como exigía el surrealismo a sus adeptos. Explica la historia del 'Libro', visiblemente entusiasmado con la rebeldía que traen los primeros románticos, rebeldía ante la tradición que se afirma y confirma en el siglo XX. El 'Libro' alegorizante, esteticista y transmisor de ideas universales, como el clasicista, deriva en el romanticismo en un objeto personal, en la búsqueda de un individuo, en la expresión de una conciencia. Cortázar prefiere claramente un romanticismo, frente a los otros muchos que han nacido como fruto de esta exacerbación del individuo, que ame el Libro por razones principalmente existenciales, de afirmación individual; tal, nos dice, es el caso de Chateaubriand, de Byron, de Leopardi, incluso de William Blake. Es decir, ni ética ni estética, sino la literatura como tendencia a "la expresión total del hombre". Y se inclina, "con temerosa maravilla ante esos escritores del pasado donde asoma, proféticamente, la conciencia del hombre total",

Cortázar llega a la literatura con este imperativo sobre el hombre, sobre el escritor que antes de ser escritor es un hombre que realizará plenamente su insatisfacción y la de los demás en el arte, en la acción o en el amor. Es el hombre nuevo del surrealismo, sumido como todos en una angustia, pero es el hombre que todo lo pide del hombre, y sólo del hombre, "en cuanto cree que el hombre posee virtualmente sus últimas posibilidades, está solo frente a su destino, puede decidirlo como individuo y como especie, y debe escoger su futuridad al escoger su presente"

Cuatro años después de que escribiera estas afirmaciones, se publicaría Bestiario, ¿cómo pensar que la preocupación de Cortázar no era el hombre? Un hombre superlativo, un hombre creado de nuevo y sin ningún Dios ni posibilidad de salvación que no sea la de su complejísimo, metafísico e intuitivo actuar: "La acción se manifiesta entonces simultáneamente en autorrealización y búsqueda de contacto para instituir la comunidad". Con este breve apunte, antes que hablar del surrealismo y el existencialismo en Cortázar, tema de sumo interés pero que nos desviaria del hilo de nuestro discurso, queremos señalar la imagen del hombre que deriva de esta parte de su obra crítica, un ser solitario y angustiado, pero un ser poderoso por la confianza que pone, única y exclusivamente, en la exhortación a utilizar sus fuerzas intelectuales, fisicas y emotivas.

Ahora bien, volviendo a la etapa de escritura de El perseguidor, veamos una carta que le envía a su amigo Jean Bernabé, cuando han pasado diez años de esta declaración de poderío sin sombras que reside en el

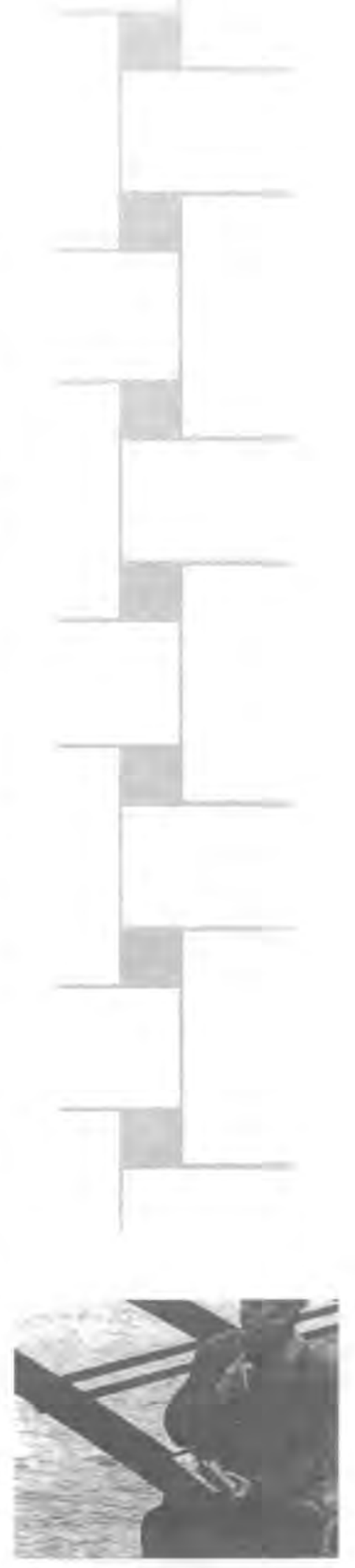


hombre. El 27 de julio de 1959, Cortázar hablará a uno de sus mayores confidentes, en tono intimista, de un tipo de hombre muy distinto a aquél

que, con su lúcido e intuitivo accionar, principalmente en el quehacer literario, encontraría su reino en esta tierra.

En esta carta, el autor comienza con una apreciación sobre la amistad que difiere de la actitud programática de unirse a los semejantes que destellaba en el manifiesto. Le dice a este gran amigo que la amistad es con unos pocos, y es algo que se nos da, porque "somos tan complicados, nosotros, $\tan$ llenos de misteriosos resortes, de resonancias secretas, de alianzas y hostilidades [...]. De la simpatía a la amistad hay un largo itinerario, que pocos son capaces de seguir hasta el final" ". Y con esta introducción, que prepara el terreno para algo que él llamará luego una confesión, se descubre ante Jean Bernabé como un Cortázar anodino, burgués, cotidiano, vulgar:

En el fondo, Jean, lo que ocurre es que en mí no hay mucho de interesante, no hay mucho que mostrar ni que contar. No crea que me hago el interesante, o que peco de modesto. Lo que escribo es sobre todo invención, y es invención porque no tengo nada que recordar que valga la pena. [...] Yo, en cambio, me rompo un brazo, visito el Partenón, navego por el Ganges, pero siempre estoy como dentro de mí mismo; mis entusiasmos - que son grandes - no me arrancan del esteticismo o a lo sumo de una ansiedad de tono casi místico pero de calidad más que dudosa. [...] Mi vida de joven fue igualmente anodina" $"$.

Cortázar, el anodino, el que afirma no poder salir de sí mismo. El que ha confesado que un gran entusiasmo no alcanza para sacarlo de su esteticismo. Pero, unas líneas más adelante, no ceja en su consideración del arte, el amor o la acción - viejos mitos surrealistas - como los instrumentos predestinados a quebrantar la costumbre: "Lo que creo es que la realidad cotidiana en que creemos vivir es apenas el borde una fabulosa realidad reconquistable, y que la novela, como la poesía, el amor y la acción, deben proponerse penetrar en esa realidad" ".

Sin embargo, aunque retome este antiguo axioma, ya nos ha hablado,

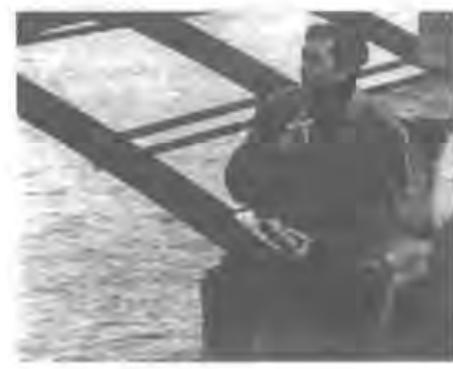
en esta carta a su amigo, del hombre que se encuentra con una pared demasiado gruesa para su entusiasmo, de que todo es oscuro, y de que él mismo es "tan poco capaz de romper con tanto hábito, tanta comodidad mental y física, tanto mate a las cuatro y cine a las nueve" 12 ,

Sobre los perfiles de este hombre, y no del viejo héroe del surrealismo, haremos una lectura de El perseguidor, porque a nuestros ojos, por este tipo de hombre que se sabe deseoso, con grandes entusiasmos, pero que a la vez se reconoce, intimamente, incapaz de reconquistar esa fabulosa otra realidad; por esta novedad de lo humano $\tan$ humano, $\tan$ llanamente 
humano en su deseo y en su incapacidad sentimos que "El perseguidor es diferente" 13 .

Una cuestión previa atraviesa nuestra interpretación: el franquear esa puerta, el acceder a esa realidad que está al borde de esto tan anodino, si no está reservada al hombre normal, ¿es porque sólo la demencia, la đroga, la genialidad, o el otro instrumento de prestidigitación tan cortazariano, el juego, pueden con ella, son accesos posibles?

El perseguidor-protagonista de nuestro cuento recorre, atento a una suerte que lo descoloca continuamente y buceando en sus fuerzas, este existencial intento de ascender. Sus dos epígrafes hacen referencia a los extremos entre los que oscila el personaje, y que podríamos llamar la 'autenticidad' y la 'máscara'. El primero es un versículo del Apocalipsis: "Sé fiel hasta la muerte" (Ap. 2, 10) y el segundo, un verso de Dylan Thomas: "Oh make me a mask". Proponemos la lectura de El perseguidor describiendo cómo son y adónde conducen estos caminos que transita Charlie Parker, el gran jazzman del siglo XX, protagonista de esta pequeña joya de Julio Cortázar.

Lo que leemos son los comentarios de Bruno, el biógrafo de Charlie Parker, a sus encuentros y charlas con el músico. Es un hábil contrapunto el de estas dos voces: la de profundidades insondables y grandes intuiciones del genio del jazz -drogadicto, suicida, visionario e incorregible- y la más superficial y lógica de su biógrafo, un hombre que detesta lo amoral al igual que detesta las camisas sucias.

El primero de los epígrafes, "Sé fiel hasta la muerte", es el consejo del Ángel del Apocalipsis a la Iglesia de Esmirna, que continúa con estas palabras: "y te daré la corona de la vida". ¿A qué puede ser fiel Charlie Parker, si en su inconstancia es igualmente capaz de tocar los tres mejores minutos de la historia del jazz como de romper contra el suelo su saxo, inmediatamente después, porque no soporta la idea de que lo que toca hoy es lo mismo que tocará mañana? Pero el epígrafe es claro: "Sé fiel hasta la muerte". ¿A qué ser fiel para obtener la corona de la vida? Debe valer realmente la pena para proponerle a Parker, justamente a él, la fidelidad.

El mismo Charlie Parker se afana en hablar de ello, aunque Bruno quiera llevarlo por otros derroteros. Ser fiel a los momentos en que el instante fue un destello de la eternidad, gracias a ciertos gloriosos soplidos en su saxo:

Bruno, si yo pudiera solamente vivir como en esos momentos... Entonces un hombre, no solamente yo sino ésa y tú y todos los muchachos, podrían vivir cientos de años, si encontráramos la manera podríamos vivir mil veces más... ${ }^{14}$.

La música me sacaba del tiempo, aunque no es más que una manera de decirlo. Si quieres saber lo que realmente siento, yo creo que la música me metía en el tiempo ${ }^{15}$.
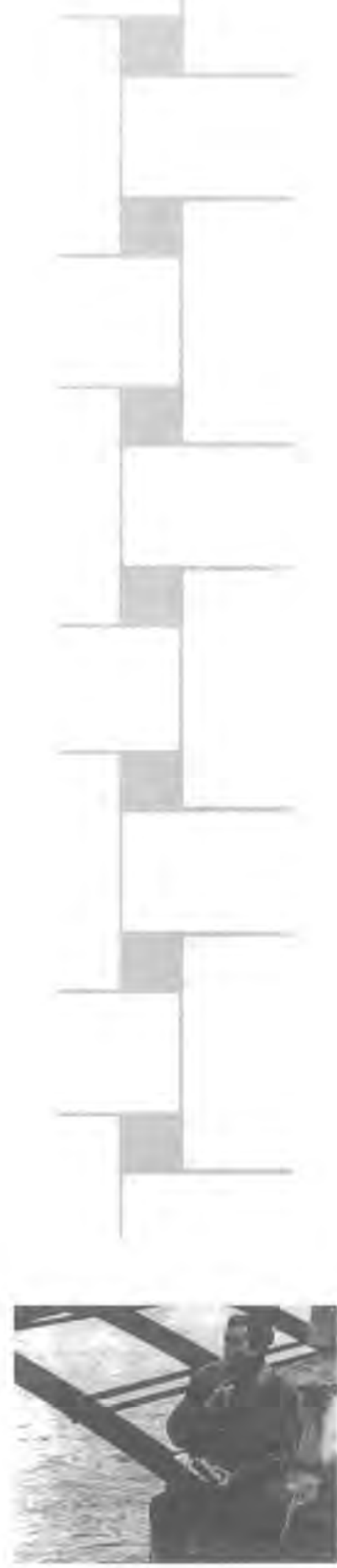
Y lo que había a mi lado era como yo mismo pero sin ocupar ningún sitio, sin estar en Nueva York, y sobre todo sin tiempo, sin que después...sin que hubiera un después...Por un rato no hubo más que siempre... ${ }^{16}$.

Ser fiel a ese deseo inmenso, ser fiel a lo que dice la insatisfacción, ser fiel a la sed de otra cosa, o conformarse y vivir como ratones que buscan un queso pero caen en la trampa:

Me pareció...pero hay que ser idiota...me pareció que un día iba a encontrar otra cosa. No estaba satisfecho, pensaba que las cosas buenas, el vestido rojo de Lan, y hasta Bee, eran como trampas para ratones [...] Trampas para que uno se conforme, sabes, para que uno diga que todo está bien [...] hasta el jazz, sí, hasta el jazz, eran como anuncios en una revista, cosas bonitas para que me quedara conforme... ${ }^{17}$.

Ser fiel al momento en que ha podido espiar, por una rendija, la existencia de algo más que 'cosas bonitas'; a no tapar esa pequeña y luminosa grieta: "Trampas querido...porque no puede ser que no haya otra cosa, no puede ser que estemos tan cerca, tan del otro lado de la puerta" ${ }^{\text {". . }}$

Bruno comenta las intuiciones vertiginosas de Charlie, pero apenas pisa la calle piensa que no son más que fantasías, producto de la marihuana que consume el músico. Pero hay un momento, mientras las está escuchando, en que son tan reales y golpean tanto como un martillo metiendo una cuña: "cuando Johnny me lo está diciendo siento que hay algo que quiere ceder en alguna parte, una luz que busca encenderse, o más bien como si fuera necesario quebrar alguna cosa, quebrarla de arriba abajo como un tronco metiéndole una cuña y martillando hasta el final"19.

En esos momentos se da cuenta de que para que estas palabras calen le haría falta olvidar su dialéctica, le haría falta un cambio en su voz, un cambio de posición, como cuando uno se pone de rodillas para rezar:

Me parece comprender porqué la plegaria reclama instintivamente el caer de rodillas. El cambio de posición es el símbolo de un cambio en la voz, en lo que la voz va a articular, en lo articulado mismo [...] Cuando llego al punto de atisbar ese cambio, las cosas que hasta un segundo antes me habían parecido arbitrarias se llenan de sentido profundo, se simplifican extraordinariamente y al mismo tiempo se ahondan ${ }^{20}$

Pero el verso de Dylan Thomas, uno de los tantos que el músico lleva en un sucio cuadernito que lee y relee antes de los ensayos, habla de lo opuesto a esta desnudez, a este caer de rodillas en el que todo se simplifica: "Oh make me a mask" son las palabras que Charlie pronuncia antes de morir. 
El alucinado jazzman pide una máscara, porque cuando se mira sin tapujos, se sabe una suma de vacios que no puede soportar:

No había más que fijarse un poco, sentirse un poco, callarse un poco, para descubrir los agujeros [...] En la mano, en el tiempo, en el diario, en el aire: todo lleno de agujeros, todo esponja, todo como un colador colándose a sí mismo [...] Anoche se me ocurrió mirarme en este espejito, y te aseguro que era tan terriblemente dificil que casi me tiro de la cama ${ }^{21}$.

A Charlie le aterroriza la idea de que la imagen que le devuelve el espejo sea la del hombre, que sólo eso sea el hombre. "Lo que soy de veras", quién lo sabe, pero eso es lo que Parker hubiera deseado tocar, y de lo que quisiera que se hablara en su biografia, como advierte a su amigo el crítico, que cree haberlo dicho todo sobre el músico y su creación: "Bruno, el jazz no es solamente música, yo no soy solamente Johnny Carter""22.

Ser fiel, o la máscara. ¿Pero cómo ser fiel si el hombre hace aguas por todos esos agujeros apenas se mira "un poco"?

En la última conversación de estos dos amigos, Charlie Parker, el perseguidor, intenta explicar al biógrafo que a su libro le falta algo, que hay algo de lo que el libro no habla, "Bruno, de lo que te has olvidado es de mí [...] ¿Cómo te lo puedo explicar?”23. Y para explicar quién es 'él', quién es Charlie Parker,-le repite tres veces, con unos interminables puntos suspensivos, la parte más importante de su biografia, la que Bruno ha olvidado mencionar en su libro: "Bruno, yo me voy a morir sin haber encontrado... [...] Sin haber encontrado... -repite-. Sin haber encontrado..., ${ }^{24}$.

\section{3}




\section{Notas}

' Véase Omar Prego Gadea, La fascinación de las palabras. Conversaciones con Julio Cortázar, Barcelona, Muchnik Editores, 1985, p. 67.

${ }^{2}$ Prólogo de Mario Vargas Llosa a Julio Cortázar, Cuentos Completos (1945-1966), Buenos Aires, Alfaguara, 1998, p. 22.

${ }^{3}$ Luis Harss, Los nuestros, Buenos Aires, Sudamericana, 1966, pp. 273 - 274.

${ }^{4}$ Prólogo de Jorge Luis Borges a Julio Cortázar, Cuentos, Barcelona, Ed. Orbis, 1986, p. 3.

s Julio Cortázar, Obra crítica, Vol.1, Madrid, Alfaguara, 1985, p. 40.

${ }^{6}$ Ibidem, p. 62.

7 Ibidem, p. 163.

${ }^{8}$ Ibidem, p. 120.

Julio Cortázar, Cartas 1937-1963, Madrid, Alfaguara, 2002, p. 395.

${ }^{10}$ Ibidem, p. 396.

"Ibidem, p. 397.

${ }^{12}$ Ibidem, p. 397.

${ }^{13}$ bidem, p. 397.

${ }^{14}$ Julio Cortázar, Obras Completas 1: Cuentos, Barcelona, Galaxia Gutenberg, 2003, p. 320.

${ }^{15}$ Ibidem, p. 314.

${ }^{16}$ Ibidem, p. 358.

${ }^{17}$ Ibidem, p. 358.

${ }^{18}$ Ibidem, p. 359.

${ }^{19}$ Ibidem, p. 321.

${ }^{20}$ Ibidem, p. 330.

${ }^{21}$ Ibidem, p. 337.

${ }^{22}$ Ibidem, p. 356.

${ }^{23}$ Ibidem, p. 357.

${ }^{24}$ Ibidem, p. 357.

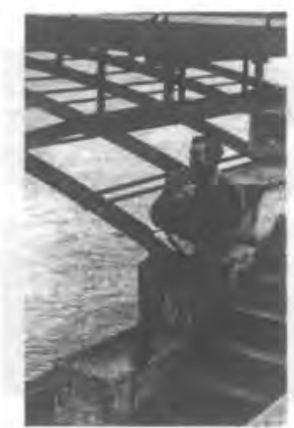

